\title{
Experimental Research Regarding the Plastic Flow of Aluminium Alloy EN AW-7075 in Closed-die Forging Without Flash
}

\author{
MARIA KAPUSTOVA ${ }^{1}$, J OZEF BILIK', MARTIN SAHUL' ${ }^{1}$, MARTIN RIDZON ${ }^{2}$, CRISTINA STEFANA MIRON BORZAN ${ }^{3 *}$ \\ ${ }^{1}$ Slovak University of Technology in Bratislava, Faculty of Materials Science and Technology, J. Bottu 25, 91724 Trnava, Slovakia \\ ${ }^{2}$ ZP Research and Development Centre, Kolkaren 35, Podbrezova, Slovakia \\ ${ }^{3}$ Technical University of Cluj-Napoca, 103-105 Muncii Str., 400641, Cluj Napoca, Romania
}

\begin{abstract}
The paper describes an innovative method of production of non-ferrous drop forgings, a manufacturing method based on closed die forging without flash. From economic point of view, this method is very interesting for production, due to small quantity of lostmaterial. The research was verified using DEFORM 3D software. In this way can be better understood the principles of forging process and can be analyzed the plastic flow of the material into the die cavity. This experiment was successfully performed at laboratory conditions and the results will be applied in practice.
\end{abstract}

Keywords: closed-die forging, plastic flow, flash, ideal forging blank, computer simulation

Since aluminium is considerable lighter than steel, several industries, such as aeronautics and the car industry, have chosen to use aluminium alloys [1].

At present the most of drop forgings made out of aluminum alloys are produced by open die forging with flash. Flash represents a material loss that results from the forging technology and depends on complexity of drop forging shape. Usually it represents $20 \%$, however it may represent up to $50 \%$ of the forged piece weight. Theoretical basics and division of die forging technologies is described in listed references [2-6]. Competitiveness in automotive industry compels the production companies to introduce new advanced and economic processes of aluminium drop forgings production. Application of die forging process without flash using closed dies belongs to innovative methods of forging.

Al alloys of series 7000 have main alloying element $Z n$ in amount of $1-8 \%$. Due to presence of magnesium, these alloys achieve highest strength properties out of all aluminum alloys. However, compared to maximum strength properties, these alloys have low corrosion resistance. But it is possible to increase the corrosion resistance by heat treatment, at the expense of strength properties. Al alloy is used in various industrial areas in form of pressed and rolled semi-products or drop forgings [7-10]. It is determined for highly stressed parts, working on a long-term basis to the temperature $100-120^{\circ} \mathrm{C}$. Due to its low weight and mechanical properties, the alloy EN AW -7075 is widely used especially in aviation and automotive industry.

Modern engineering CAD systems and simulation software are important for development and application of advanced methods of precision drop forging in production practice. Computer simulation helps better understand the principles of the forging process and especially follow the plastic flow of material in die cavity during its filling. The advantage of simulation software is the fact that these programs verify correctness of design of technological parameters and tool shape prior to initiation of production. These programs perform experiments out of real production with no direct interferences to production operation; therefore they help reduce total production costs [11-13].

From the viewpoint of shape complexity of forgings, technology of closed die forging has some limitations. Suitable forging shapes are especially simple rotary or longitudinal shapes; less suitable are very complex shapes and forked $(Y)$ shapes.

\section{Experimental part}

Shape of drop forging and material

A lever-shaped forged piece was designed for research purposes, its shape and dimensions are illustrated in figure 1. At designing of drop forging shape the standards and principles of drop forging creation for closed dies (radiuses, bevels, wads, etc.) were respected.

For the experiment of forging without flash of nonferrous alloys on Al basis the aluminum alloy marked as EN AW-7075 (AlZn5,5MgCu) was selected. Chemical composition of Al alloy according to norm EN AW-7075 shows table 1.

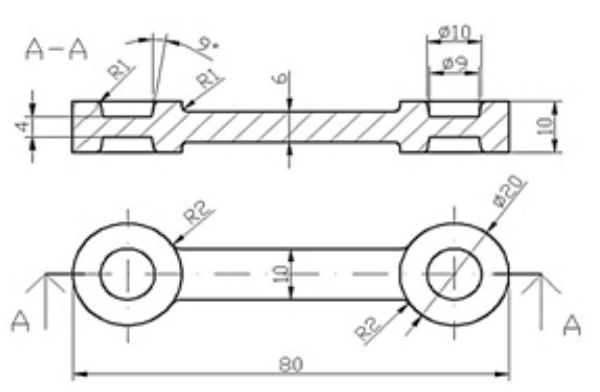

Fig. 1 Shape and dimensions of forging Lever

Table 1

CHEMICAL COMPOSITION OF AL ALLOY EN AW-7075 (wt. \% )

\begin{tabular}{|l|c|c|c|c|c|c|c|c|c|c|c|}
\hline Element & $\mathrm{Zn}$ & $\mathrm{Mn}$ & $\mathrm{Mg}$ & $\mathrm{Cu}$ & $\mathrm{Cr}$ & $\mathrm{Fe}$ & $\mathrm{Si}$ & $\mathrm{Zr}$ & $\mathrm{Ti}$ & Oth. (total) & $\mathrm{A} 1$ \\
\hline Content & $5.1-6.1$ & 0.3 & $2.1-2.9$ & $1.2-2.0$ & $0.18-0.28$ & 0.5 & 0.4 & 0.25 & 0.2 & 0.15 & Remainder \\
\hline
\end{tabular}

\footnotetext{
*email: borzan_cristina@ymail.com; Phone: 0040757066733
} 


\section{Selection of upper forging temperature}

An important technological parameter at die forging is appropriate forging temperature. Recommended interval of forging temperatures for Al alloy EN AW-7075 ranges from 350 to $500^{\circ} \mathrm{C}$. For production of drop forging Lever is typical one-cavity die placed in forging mechanical press. From economic point of view itis appropriate to determine upper forging temperature within area of lower temperatures, i.e. from 380 to $400^{\circ} \mathrm{C}$. It is necessary to verify by technological test if Al alloy is suitable for forging at selected temperatures.

For the verification of forgeability of selected Al alloy, the technological test of upsetting according to Zidek is used. The test is based on deformation of cylindrical test sample with four notches at defined temperatures. Samples with diameters of $\varnothing 30 \times 40 \mathrm{~mm}$ are deformed to the extent of one third of their height (i.e. height dimension of the sample after upsetting is approximately $26.7 \mathrm{~mm}$ ). The presence of cracks in notches is evaluated. The principles of these methods are described in detail in listed literature $[14,15]$. There are five classification degrees used for forgeability evaluation according to appearance of cracks in cylinder notches: 1 - without cracks (good forgeability); 2 -small separated cracks (lowered forgeability); 3-small cracks in all notches (medium lowered forgeability); 4 - medium cracks in all notches (downgraded forgeability); 5 - big cracks (fractures) in all notches [16].

Forgeability of Al alloy EN AW-7075 was considered by mean value, which is given by classification level according to examined temperatures. Testing samples were made from a bar heat rolled, which was provided without any heat treatment. In order to harmonize mechanical properties and obtain fine-grained structure it was necessary to anneal the testing cylinders. The shape and dimensions of a test sample are shown in figure 2.
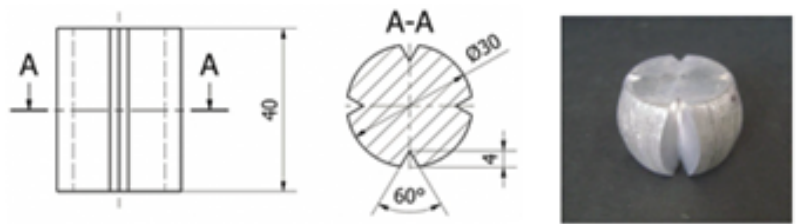

Fig. 2 Dimensions and shape of test sample prior to the test and after the test

The upsetting tests were performed at selected temperatures 350,380 a $400{ }^{\circ} \mathrm{C}$ and five testing samples were examined for each temperature. The cylinders with notches were upset on mechanical press by one third of its height and the appearance of cracks in notches was evaluated. Test samples were evaluated through stereo microscope type ZEISS STEMI 2000-C.

\section{FEM simulation of forging process}

When using Finite Element Method (FEM), the area deformed by forming is separated to finite amount of elements with particular shape and each element has its own approximation. In order to perform areas tasks, a triangular element and approximation function of linear or cubic multi-nominal type are chosen. In the area of bulk forming for a calculation with the help of FEM method mostly bulk/volume elements (3D-elements) are used. FEM method using volume elements is called FVM (Finite Volume Method). The principles of these methods are described in detail in listed literature $[17,18]$. Balance equations are prepared for particular elements and a system of differential equations will develop. After solving the above mentioned equations, we may achieve results of strain, deformation and temperature fields in a formed body and to follow the flow of solid-plastic or elastic-plastic bodies $[19,20]$.

For numeric analysis of forming processes were used eqs. (1)-(4) for calculation of effective stresses óef and effective strains $\varphi$ ef

$$
\sigma_{e f}=\frac{1}{\sqrt{2}} \sqrt{\left|\sigma_{1}-\sigma_{2}\right|^{2}+\left|\sigma_{2}-\sigma_{3}\right|^{2}+\left|\sigma_{3}-\sigma_{1}\right|^{2}}
$$

(1)

$$
\sigma_{\mathrm{ef}}=3 \cdot \mathrm{I}_{2 \mathrm{D}} \mathrm{D}^{1 / 2}
$$

where: $I_{2 D}$ - The second (quadratic) stress deviator

$$
\begin{aligned}
& I_{2 D}=\frac{1}{6}\left[\left|\sigma_{1}-\sigma_{2}\right|^{2}+\left|\sigma_{2}-\sigma_{3}\right|^{2}+\left|\sigma_{3}-\sigma_{1}\right|^{2}\right] \\
& \varphi_{e f}=\frac{\sqrt{2}}{3} \cdot \sqrt{\left|\varphi_{1}-\varphi_{2}\right|^{2}+\left|\varphi_{2}-\varphi_{3}\right|^{2}+\left|\varphi_{3}-\varphi_{1}\right|^{2}}
\end{aligned}
$$

In order to mathematically express the plastic flow of material with hardening, a relation according to authors' Levy-Misses eq. (5) is used.

$$
\frac{\varphi_{1}-\varphi_{2}}{\sigma_{1}-\sigma_{2}}=\frac{\varphi_{2}-\varphi_{3}}{\sigma_{2}-\sigma_{3}}=\frac{\varphi_{3}-\varphi_{1}}{\sigma_{3}-\sigma_{1}}=\frac{3}{2} \frac{\varphi_{e f}}{\sigma_{e f}}
$$

where: $\varphi_{1} \varphi_{2} \varphi_{3}$ - principal strains, $\sigma_{1} \sigma_{2} \sigma_{3}$ - principal stresses

Reliability of results achieved by FEM simulation depends on correctness of definition of input parameters. Numeric simulation of forming processes usually consists of the following three phases: Pre-processing - preparation phase which includes preparation of models, i. e. inserting of geometric models in supported format from CAD system. All marginal input conditions and selection of elements, material parameters, machine parameters, etc. are entered. Processing - phase of calculations using FEM method. Post-processing - output phase of simulation software which enables to depict achieved results of FEM simulation.

Using computer simulation, defects of incorrect flow folds or unfilled places in die cavity are detected. Achieved results of FEM simulation of closed-die forging process regarding Al alloys are described in listed literature [21, 22].

\section{Post-processing of results with DEFORM-3D software}

Computer simulation of forging process regarding Al alloy EN AW-7075 was performed by DEFORM-3D software (Design Environment for FORMing). It is a highperformance simulation system designed for threedimensional (3D) analysis of material flow within broad scope of forming processes. It is a practical and effective tool for prediction of plastic material flow in forming tools for the purpose of reduction of production costs and acceleration of the whole production process. It is used for simulation of die forging and smith forging processes, rolling, extruding, drawing, etc.

Software DEFORM-3D was used for verification of correct shape of semi-product for flawless production of a forged piece Lever. A prism-shaped semi-product as well as an ideal blank-shaped semi-product were designed. The plastic flow of Al alloy in closed die cavity was verified using computer simulation. 


\section{Experimental tests}

The experiment of die forging without flash of the forged piece Lever forged from aluminium alloy EN AW-7075 was conducted in laboratory conditions. Correct selection of forging press for this experiment depends on force calculation according to the following relation:

where:

$$
\mathrm{F}=\mathrm{C} . \mathrm{k}_{\mathrm{p}} \cdot \mathrm{S}[\mathrm{N}]
$$

$\mathrm{k}_{\mathrm{p}}$ - flow stress of $\mathrm{Mg}$ alloy at forging temperature [MPa];

$S^{p}$ - plan surface of forged piece $\left[\mathrm{mm}^{2}\right]$;

C - coefficient of flow stress increase, $C=1.53$,

$$
\begin{gathered}
\left(\ln \frac{0.47 \cdot d}{r}+m^{2} \cdot \ln \frac{0.47 \cdot d_{1}}{r_{1}}\right)+\frac{2 f}{d} \cdot\left(h+m \cdot h_{1}\right) \\
m=\frac{d_{1}}{d}
\end{gathered}
$$

$\mathrm{f}$ - coefficient of friction; $d, d 1, r, r l a h, h 1$-dimensions of forged piece $[\mathrm{mm}]$ according to figure $3 a ; \mathrm{f}=0.3 ; \quad \mathrm{C}=$ 5.53; $\mathrm{S}=1028.3 \mathrm{~mm}^{2}-$ value was calculated using CAD system as shows figure $3 \mathrm{~b} ; \mathrm{kp}=40 \mathrm{MPa} ; \mathrm{F}=216.2 \mathrm{kN}$.

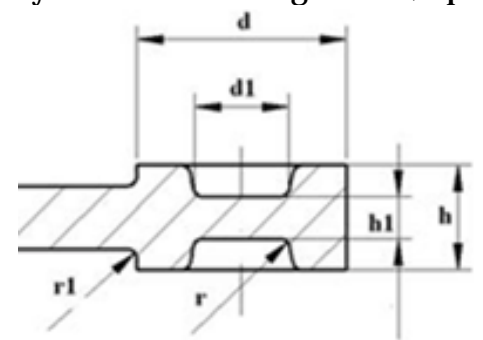

a)

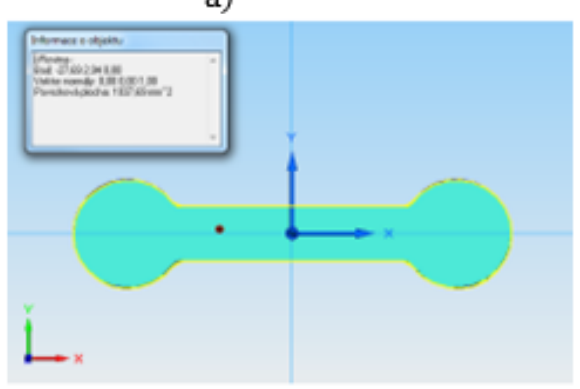

b)

Based on the calculations of forging force for experimental purposes, a mechanical screw press LV100 with nominal power $1000 \mathrm{kN}$ was chosen from available machines. Forging tool, i.e. two-piece closed die was made of steel STN 419663 (55NiCrMoV7) and subsequently it was heat-treated to $48 \mathrm{HRC}$.

In figure 4 the mentioned mechanical press and forging tool used at forging of Lever piece are illustrated.
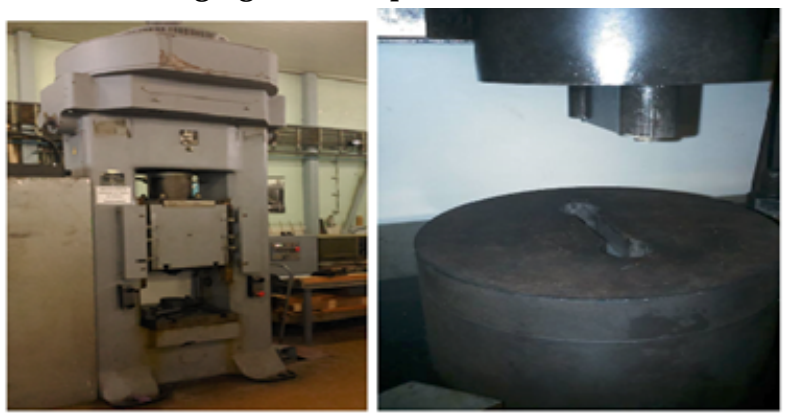

Fig. 4 Mechanical screw press LV100 and forging tool

Based on the plastic flow in die cavity verified by the simulation, the semi-product with ideal forging blank shape was selected for the real experiment. The semi-product shape was made by turning operation from a bar colddrawn made of aluminium alloy EN AW-7075. Heating of the semi-product to the forging temperature $400^{\circ} \mathrm{C}$ was conducted in electric furnace. Achieved temperature of semi-product as well as temperature of forging die was verified by optical pyrometer.

\section{Results and discussions}

Success of forging process performance in closed die regarding aluminium alloy depended on correctly chosen technological parameters. Closed-die forging process is influenced by upper forging temperature of the material as well as by pre-heating temperature of the tool. Optimization of the tool temperature along with semi-product temperature and type of forging machine are important factors at designing the technological forging process $[22,23]$.

For selection of upper forging temperature, the according to the Zidek classification, the cylindrical test samples with diameters of $\varnothing 30 \times 40 \mathrm{~mm}$ were analysed. The appearance of cracks in particular notches as well as their size and amount was observed. The results of measurements using the stereo microscope are shown in figure 5.

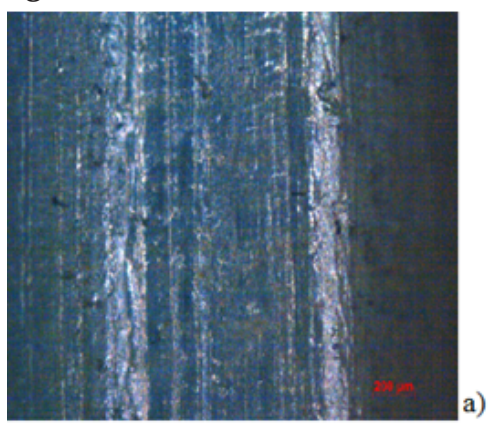

Fig. 5 Detail of a notch: a) without cracks b) with cracks

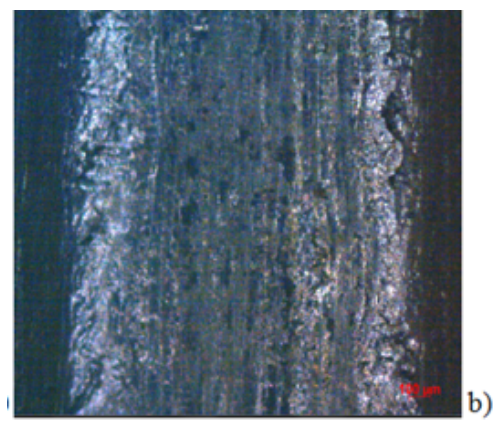

Accordingly the appearance of cracks in notches according to classification degrees at particular temperatures was evaluated the results are stated in table 2.

Table 2

EVALUATION OF CRACKS IN NOTCHES OF SAMPLE

\begin{tabular}{|lccc|}
\hline Temperature $\left[{ }^{\circ} \mathrm{C}\right]$ & 350 & 380 & 400 \\
\hline Classification degree & 2 & 1 & 1 \\
\hline
\end{tabular}

Reached value 1 defines good forgeability of Al alloy EN AW- 7075 at testing temperatures 380 and $400^{\circ} \mathrm{C}$. Random cracks in notches appeared at testing temperature $350^{\circ} \mathrm{C}$ and this temperature is not recommended as upper forging temperature.

The prism-shaped semi-product as well as the ideal blank-shaped semi-product are shown in figure 6 and figure7a. Compared to prism-shaped semi-product, semiproduct with ideal forging blank shape is preferable as it did not require transport of such a large volume of material in die cavity.

Simulation shown in figure 6 confirmed visible defects on the drop forging surface and inappropriate plastic flow of material concerning used prism-shaped semi-product. 

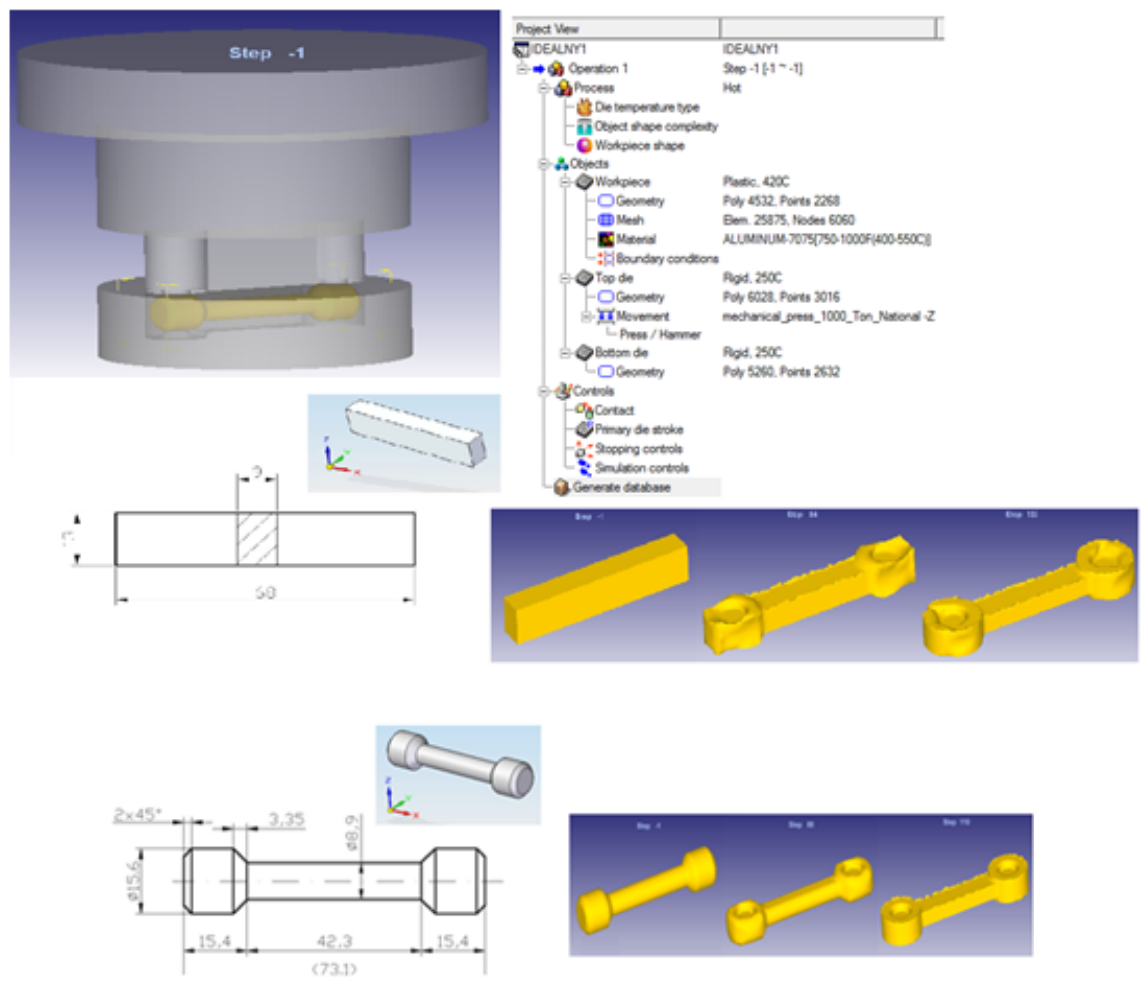

a)
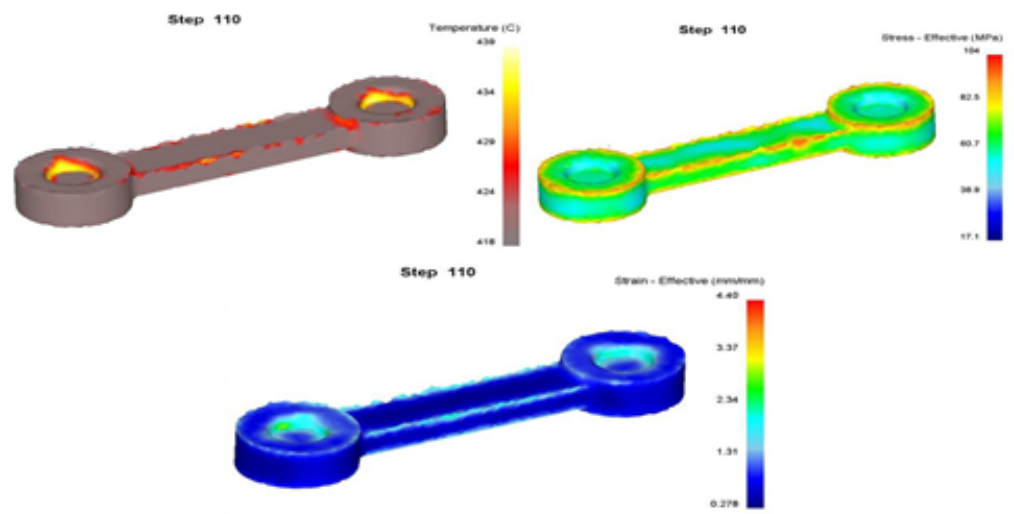

b)

Perfect filling of cavity by forged material and accuracy of forged piece shape were achieved by the semi-product with ideal forging blank shape. Thus, this shape of semiproduct was selected for experiment performance.

The results of post-processing, i.e. output phase of simulation process are the distributions of forging temperatures, stresses and strains illustrated in figure $7 \mathrm{~b}$.

Achieved logarithmic strain degrees in the forged piece within phase of its final shape are presented. The highest values of logarithmic strain degree are in heads (i.e. wad areas) of the forged piece. Maximal strain values 1.36 achieved by simulation process are comparable to real strain value according to the calculation of eq. (9):

$$
\varphi_{\max }=\ln \frac{h_{0}}{h_{1}}=\ln \frac{15,6}{4}=\ln 3,9=1,36
$$

Colour scale for evaluation of simulation courses shows highest values of true strain degree as well as highest temperatures reached in forged piece during finishing of its shape. These highest temperatures were achieved in drop forging heads, i.e. in area of wad creation, where the material was deformed by pressure at the most.

The semi-product with appropriate shape for forging of final forged piece in single cavity closed die was selected
Fig. 6. Incorrect material plastic flow in closed die cavity
Fig. 7 a). Correct material plastic flow in closed die cavity b) Results of output stage of computer simulation based on the numerical simulation. The chosen semiproduct with ideal forging blank shape and heating up to upper forging temperature $400^{\circ} \mathrm{C}$ should ensure perfect filling of closed die cavity. The used aluminium alloy - type EN AW-7075 belongs among alloys with higher strength and lower formability. The fact that used screw press has filled the die cavity during three to four strokes of press ram as well as prolongation of forging time caused decrease of forging temperature of forged material.

It was interesting to find out that the mentioned alloy responded very sensitively to the forging temperature decrease during the forging process. The failure of integrity of forged material occurred in places of the highest strain, i.e. in the heads of the forged piece Lever, as shows figure 8.

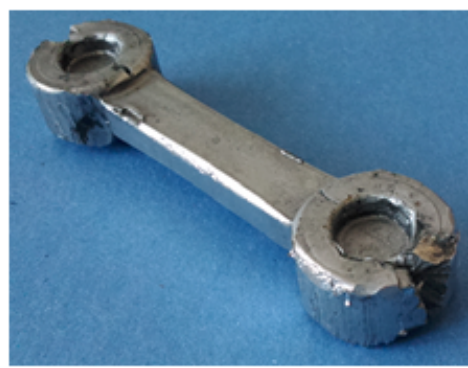

Fig. 8. Forged piece with a visible crack 


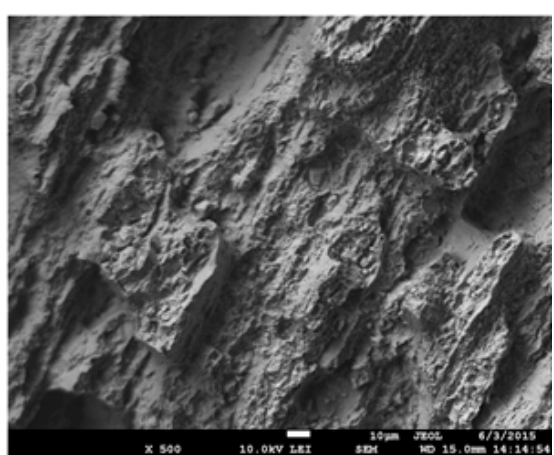

Fig. 9. Analysis of the fracture

Quasi brittle fracture with wood morphology was observed. It could be related with depletion of plasticity. JEOL JSM $7600 \mathrm{~F}$ high resolution scanning electron microscope at regime of secondary electron imaging was utilized to observe fracture areas (fig.9). The appearance of cracks in the forged piece made of material type AW 7075 determined for aviation industry is described also in literary source [24].

In order to forge the defect-free shape of forged piece Lever, it was necessary to reduce the number of strokes of screw press on two, precisely meet recommended forging temperature $420^{\circ} \mathrm{C}$, and also to increase the temperature of die pre-heating to $350^{\circ} \mathrm{C}$. In this way the final drop forging without cracks or other defects on the surface was achieved, with required dimension accuracy, as illustrates figure 10.

A slight fin occurred on the forged piece, resulting from a slit compensation in tool. This fin must be removed by grinding.

\section{Conclusions}

Drop forgings made of light non-ferrous alloys are still more widely applied especially in automotive industry, due to their low weight which is an important factor in order to achieve economic and ecological operation of vehicles.

Another significant factor for their application is also production price, as introduction of closed-die forging without flash brings cheaper production of drop forgings. However, the proposed technology has a disadvantage - it is appropriate only for lever and ring shaped forged pieces, i.e. for production of simple shaped forged pieces.

Although this research of precision closed-die forging of non-ferrous alloys was performed in laboratory conditions, brings in the same time, valuable information for the production practice.

After verification of suitability of designed semi-product with ideal forging blank shape using simulation software, this semi-product was produced from a bar cold-drawn using turning (machining). In case of series production of the forged pieces Lever, the mentioned semi-productshould be manufactured by more effective method, e.g. cross wedge rolling. Although for production of the forged piece Levera mechanical crank press would be more appropriate, as this press would produce the final shape of this forged piece during one stroke, a less appropriate forging screw press was used for this experiment and was proved that it
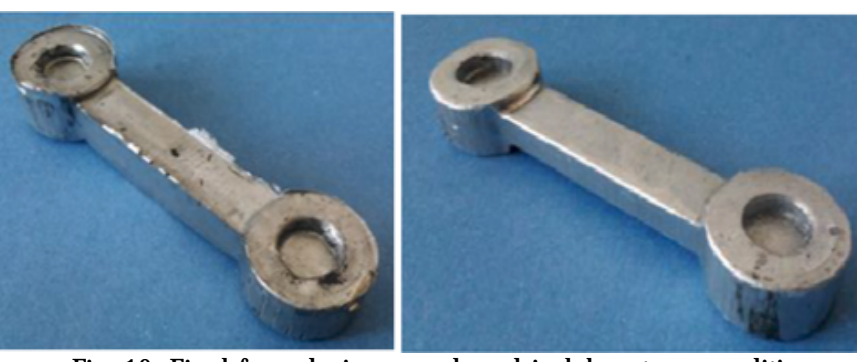

Fig. 10. Final forged piece produced in laboratory conditions

is possible to forge the aluminium alloys by innovative, more effective technology (closed-die forging without flash).

\section{References}

1. SERBAN, N., BUTU, M., COJ OCARU, V.D., Mat. Plast., 53, no.4, 2016, p. 617

2. E. DOEGE, B. A. BOHNSAK, J of Materials Processing Technology, 98(2), 2000, p. 165.

3. T. ALTAN, G. NGAILE, G. SHEN, ASM International, Ohio, USA, 2005, p. 319.

4. R. DOUGLAS, D. KUHLMANN, J of Materials Processing Technology, 98, 2000, p. 182.

5. M. KAPUSTOVA: Innovations in production trends for drop forging, Scientific Monographs. 1st ed. Köthen, Hochschule Anhalt, 2010.

6. M. MILUTINOVIĖ, et al, J for Technology of Plasticity, 33(1-2), 2008, p.73.

7. 0. JENSRUD, K. PEDERSEN, J of Materials Processing Technology, 80, 1998, p.156.

8. AA. ALALYKIN, W.BOITSOV, SE. GUTMAN, Metall, 56, 10, 2002, p. 630.

9. DB.SHAN, Z. WANG, Y. LU, J of Materials Processing Technology, 72 (3), 1997, p. 403.

10. T.S. BEN NASE, G. KRALLICS, Acta Polytechnica Hungarica, 11 (7), 2014, p. 103.

11. R.S. LEE, J.L. JOU, J of Materials Processing Technology, 140, 2003, p. 43.

12. K.SHIN, S. CHI, N. KIM,J of Mechanical Science and Technology, 24(3), 2010, p. 639.

13. B.A.BEHRENS, CIRP Annals Manufacturing Technology, 57, 2008, p. 305.

14. M. FOREJT, M. PISKA: Theory of machining, forming and tools, CERM, Brno, 2006.

15. W.F. HOSFORD, R. M. CADDELL: Metal Forming: Mechanics and Metallurg, Cambridge University Press, New York, USA, 2011.

16. M. KAPUSTOVA, Applied Mechanics and Materials, Vol. 421, 2013, p. 229.

17. S. KOBAYASHI, S.I. OH, T. ALTAN: Metalforming and the Finite-Element Method, Oxford University Press, London, 1989.

18. EDWARD R. CHAMPION, JR.: Finite ElementAnalysis in Manufacturing Engineering, McGraw-Hill, Inc, New York, 1993.

19. P.M. DIXIT, U.S. DIXIT: Modeling of Metal Forming and Machining Processes by FiniteElementand SoftComputing Methods, Springer Verlag, London, 2008.

20. F. LIU, et all, Transactions of Nonferrous Metals Society of China,15 (2), 2005, p. 136.

21. F. LI, JF. LIN, GN. CHU, JOM, 61(8), 2009, p. 57.

22. LH.LANG, AJ .XU, F. LI, JOM, 64 (2), 2012, p. 309.

23. R. BIGOT, S. LELEU, P. MARTIN, Int J Adv Manuf Technology, 21, 2003, p. 476.

24. RK. GUPTA, P. RAMKUMAR, BR. GHOSH: Engineering Failure Analysis, $13(1), 2006$, p. 1.

Manuscript received: 7.12.2016 